\title{
Aspectos fundamentais da expansão por umidade: revisão Parte II: Cinética de expansão e sua determinação
}

\section{(Fundamental aspects of the moisture expansion: review Part II: Kinetic of expansion and its determination)}

\author{
R. R. Menezes ${ }^{1}$, L. F. Campos ${ }^{2}$, G. de A. Neves ${ }^{2}$, H. C. Ferreira ${ }^{2}$ \\ ${ }^{I}$ CPGCEM, Laboratório de Síntese e Processamento de Materiais Cerâmicos - LaSP \\ Universidade Federal de S. Carlos, S. Carlos, 13565-905, SP \\ ${ }^{2}$ Departamento de Engenharia de Materiais, Centro de Ciências e Tecnologia \\ Universidade Federal de Campina Grande, Campina Grande, PB \\ rrmboca@iris.ufscar.br
}

\begin{abstract}
Resumo
A expansão por umidade (EPU) vem sendo estudada desde o século passado, no entanto, grande parte do conhecimento gerado encontrase muito disperso na literatura mundial. Assim, esse trabalho objetiva dá continuidade ao estudo de revisão dos aspectos fundamentais da expansão por umidade, com a exposição dos resultados mais relevantes a cerca da cinética do fenômeno e das particularidades de sua determinação. O texto aborda características do processo de expansão, com o detalhamento da evolução das modelagens mais utilizadas para descrever a cinética do fenômeno de EPU, bem como, apresenta uma sistemática para determinação da energia de ativação da EPU. Além disso, faz-se a descrição das metodologias de determinação da EPU dos materiais cerâmicos, evidenciando suas características, peculiaridades e pontos controversos.
\end{abstract}

Palavras-chave: expansão por umidade, materiais cerâmicos.

\begin{abstract}
Moisture expansion (ME) of ceramic materials has been studied since the last century. However, a large part of the acquired knowledge is very dispersed in the world literature. This work has as aim to continue the review about the fundamental aspects of the moisture expansion, exposing the most relevant results on the kinetics of the phenomenon and particularities of its determination. The review comprises the description of the expansion process characteristics, and the detailed evolution of the mathematical models used to describe the kinetics of the ME. Moreover, it presents a systematic approach for the determination of the ME activation energy. The review also includes the methodologies used in the determination of the ME of ceramic materials, pointing out its characteristics, peculiarities, and the controversial issues about it.
\end{abstract}

Keywords: moisture expansion, ceramic materials.

\section{EXPANSÃO POR UMIDADE (EPU)}

EPU é o termo geralmente utilizado para designar o aumento das dimensões dos materiais cerâmicos ocasionado pela adsorção de água, notadamente em tijolos, telhas e revestimentos cerâmicos. Logo após a queima e durante o seu resfriamento os materiais cerâmicos adsorvem vapor de água da atmosfera. Esse se difunde pelo corpo cerâmico e adsorve nas superfícies dos poros dentro da peça, provocando uma expansão irreversível. Essa expansão ocorre lentamente e é relativamente pequena, mas mesmo assim pode comprometer a aderência das placas cerâmicas ao contrapiso, levar ao gretamento de vidrados e conduzir a danos na estrutura das alvenarias.
A EPU "atual" é geralmente determinada pelo reaquecimento das peças, sendo a retração resultante dada com a sua expansão até o momento da requeima, enquanto que a EPU "potencial" dos corpos cerâmicos é obtida após algum ensaio que vise acelerar o processo de expansão, seguido por uma etapa de requeima. Essa conceituação geral é utilizada há dezenas de anos; no entanto, ainda existe alguma controvérsia acerca da metodologia mais adequada para se determinar a expansão dos produtos cerâmicos, seja ela a passada ou a potencialmente futura.

A primeira parte dessa revisão abordou os aspectos históricos, as causas da EPU e suas correlações com a temperatura de queima, composição química e absorção de água, evidenciando sempre a evolução cronológica das 
pesquisas. Na segunda parte dessa revisão serão abordadas as questões inerentes à cinética de expansão, também evidenciando a cronologia dos estudos, e as metodologias utilizadas para a determinação da EPU, com enfoque nas principais características e pontos controversos da questão.

\section{Cinética de expansão}

Quando a EPU de corpos cerâmicos é acompanhada por longos períodos de tempo, observa-se, normalmente, que eles expandem lentamente com uma taxa que não é constante mas que decresce com o tempo. Embora esta expansão seja geralmente linear com uma função logarítmica do tempo, os corpos podem ter rápidas expansões iniciais (algumas vezes muito elevadas), que podem ser inconsistentes com as taxas de expansão subseqüentes, refletindo a variabilidade que ocorre no comportamento de adsorção de água [1].

Não é fácil modelar a cinética de expansão de peças cerâmicas. Primeiramente, devido as suas próprias variações de composição, que influenciam o processo de adsorção; segundo, em virtude das características particulares de processamento, em especial a temperatura máxima e o tempo dos ciclos de queima; e por fim, mas não menos importante, as condições em que se deseja modelar a expansão, já que, se a análise for feita em condições ambientes, passam a ser variáveis todas as particularidades climáticas que variam de região para região.

Um dos primeiros trabalhos [2] onde se tentou modelar a expansão por umidade de peças cerâmicas admitiu que os valores de expansão em autoclave representavam a máxima EPU do corpo cerâmico, e buscou determinar qual a expansão máxima que seria obtida sob condições normais de armazenamento. Nessa pesquisa admitiu-se que a expansão é diretamente dependente do ganho de peso, assim, se o peso obtido em um tempo $t$ é $y$ e se $m$ é o máximo peso adquirido na estocagem, tem-se que a velocidade de expansão poderia ser representada por uma proporcionalidade (A). Essa proporcionalidade poderia ser expandida para a equação (B), a qual conduziria à equação (C). Então, seria possível, partindo de um gráfico de expansão natural em função do tempo, determinar a expansão máxima, $m$, através da obtenção de vários valores de $y$ e medição das tangentes nesses pontos. A precisão dessa determinação é influenciada pela precisão envolvida na medição das tangentes nos pontos $y$, e pode ser melhorada se forem utilizados vários valores de $y$ e fazendo-se uma média dos $m$ obtidos. Todavia, se colocar a proporcionalidade (A) na forma (D) e em seguida integrar, se obterá a equação exponencial (E), onde $k$ pode ser considerado como a fração da máxima expansão que ocorre em um tempo unitário. Esse método apresentou resultados de máxima expansão, $m$, próximos aos obtidos após exposição em um longo período de tempo (superior a 3 anos); no entanto, o método também requer longos períodos de exposição a fim de se obter curvas de expansão natural versus tempo, adequadas a uma extrapolação precisa.

$$
\begin{aligned}
& \frac{d y}{d t} \alpha(m-y) \\
& \frac{d y_{1}}{d t_{1}} / \frac{d y_{2}}{d t_{2}}=\frac{m-y_{1}}{m-y_{2}} \\
& m=\left(\frac{d y_{1}}{d t_{1}} y_{2}-\frac{d y_{2}}{d t_{2}} y_{1}\right) /\left(\frac{d y_{1}}{d t_{1}}-\frac{d y_{2}}{d t_{2}}\right) \\
& \frac{d y}{d t}=k(m-y) \\
& y=m\left(1-\mathrm{e}^{-\mathrm{kt})}\right.
\end{aligned}
$$

Análises de várias curvas de EPU em autoclave mostraram que a relação entre a expansão e o tempo pode ser expressa pela equação $(\mathrm{F})[3]$ :

$$
\mathrm{E}_{\mathrm{t}}=\mathrm{E}_{\mathrm{T}}\left(1-\mathrm{e}^{-\mathrm{kt}}\right)
$$

onde $E_{\mathrm{t}}$ é a expansão no tempo $t, E_{T}$ é expansão total e $k$ é uma constante. Tal equação é similar àquela de uma reação química de primeira ordem, onde $E_{T}$ é função dos componentes que com a hidratação provocam a expansão; $E_{t}$ depende da quantidade de material hidratado no tempo $t \mathrm{e}$ $k$ é uma constante de velocidade. Ressalte-se que a equação



Figura 1: EPU experimental e prevista, para tijolos (1) mal queimados e (2) bem queimados [3].

[Figure 1: Experimental and estimated ME of (1) low fired and (2) hard fired bricks [3].] 
obtida foi praticamente igual à obtida anteriormente [2]. A Fig. 1 ilustra a utilização dessa equação com relação a dados experimentais obtidos para tijolos bem e mal queimados. Pode-se observar boa concordância entre os dados e a curva obtida com uma equação da forma da equação (F), para os tijolos bem queimados, enquanto que há boa concordância apenas no estágio final para os mal queimados. Esse comportamento foi atribuído ao fato de haver grande quantidade de material amorfo nos mal queimados, com uma estrutura mais aberta e maior área específica, o que provoca uma expansão mais acentuada nos primeiros estágios do que a que seria prevista por uma equação de primeira ordem.

Estudos com corpos cerâmicos com composição aproximada de $30 \%$ de caulinita, $30 \%$ de mica, 35\% de quartzo e $2 \%$ de hematita mostram que quando se analisa a expansão em autoclave versus a expansão natural, se obtém uma relação não linear dentro do intervalo de temperaturas de 950 a $1200{ }^{\circ} \mathrm{C}$ [4]. Todavia, se for analisada a expansão obtida em autoclave versus o logaritmo da expansão natural, se obtém uma relação linear, tal como ilustrado na Fig. 2. A relação não linear expressa o fato que para este corpo a razão entre a expansão de autoclavagem e a natural varia muito com a temperatura de queima e implica que deve haver vários componentes reativos. A análise mineralógica estabeleceu que estes componentes são materiais amorfos, vítreos e minerais argilosos anidros. Materiais amorfos são igualmente reativos ao vapor de água presente no ar e ao vapor sob alta pressão e

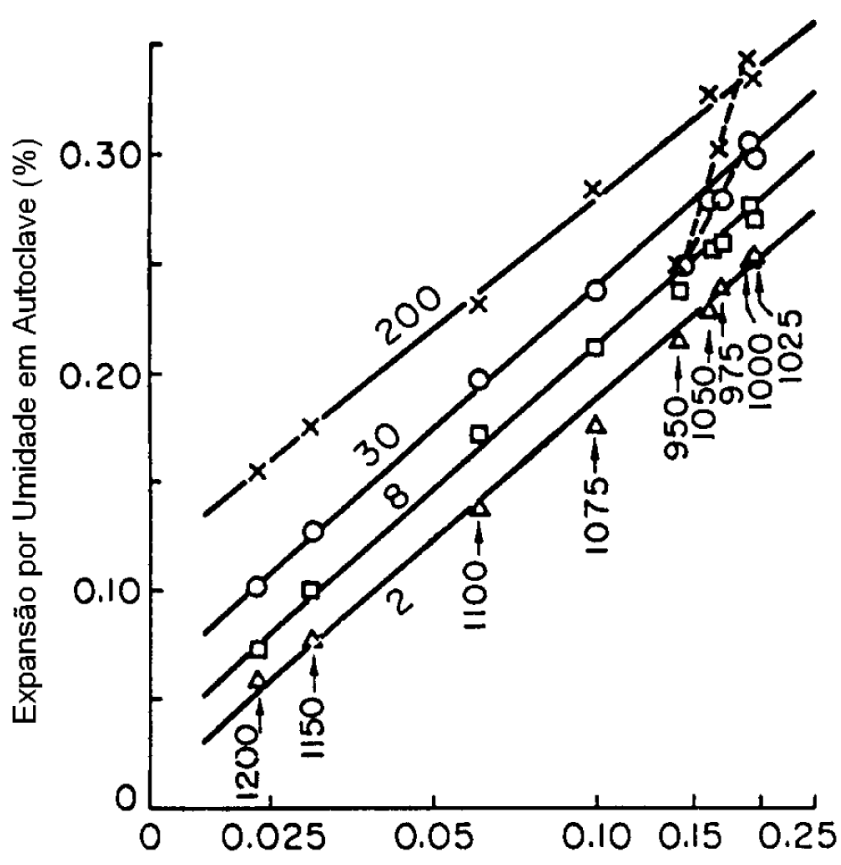

Log da Expansão por Umidade Natural (\%)

Figura 2: EPU após autoclavagem por 2, 8, 30 e 200 h versus EPU natural após 90 dias. Temperaturas de queima indicadas em ${ }^{\circ} \mathrm{C}[5]$. [Figure 2: ME after autoclaving for 2, 8, 30 and $200 \mathrm{~h}$ versus natural expansion after 90 days. Firing temperatures in ${ }^{\circ} \mathrm{C}$ [5]] temperatura em autoclave; todavia os outros componentes são muito mais reativos ao vapor em altas pressões e temperaturas. Assim, materiais contendo constituintes amorfos, anidros e vítreos irão exibir relações não lineares entre a expansão natural e a obtida com autoclavagem [4]. Não se pode afirmar que as relações serão sempre do tipo logarítmica, já que cada corpo cerâmico possui componentes que interagem de forma complexa e característica, o que requer analises individuais dos materiais [5].

É sabido que tanto a expansão natural como a obtida em autoclave aumentam rapidamente nos estágios iniciais; todavia, sua taxa de aumento decresce nos estágios seguintes. $\mathrm{O}$ interessante é que ao se analisar a expansão natural versus o logaritmo do tempo observou-se [4] uma relação linear na faixa de temperatura de 800 a $1200{ }^{\circ} \mathrm{C}$, tal como ilustrado na Fig. 3, enquanto que a relação entre a expansão obtida em autoclavagem e o logaritmo do tempo foi linear apenas na faixa de temperatura de 1000 a $1150{ }^{\circ} \mathrm{C}$. Note-se que para tempos menores que $4 \mathrm{~h}$ a linearidade ilustrada na Fig. 3 não é observada, em virtude de que todas as curvas de expansão têm que passar pela origem e isso em gráfico logarítmico ocorre apenas em $-\infty[5]$.

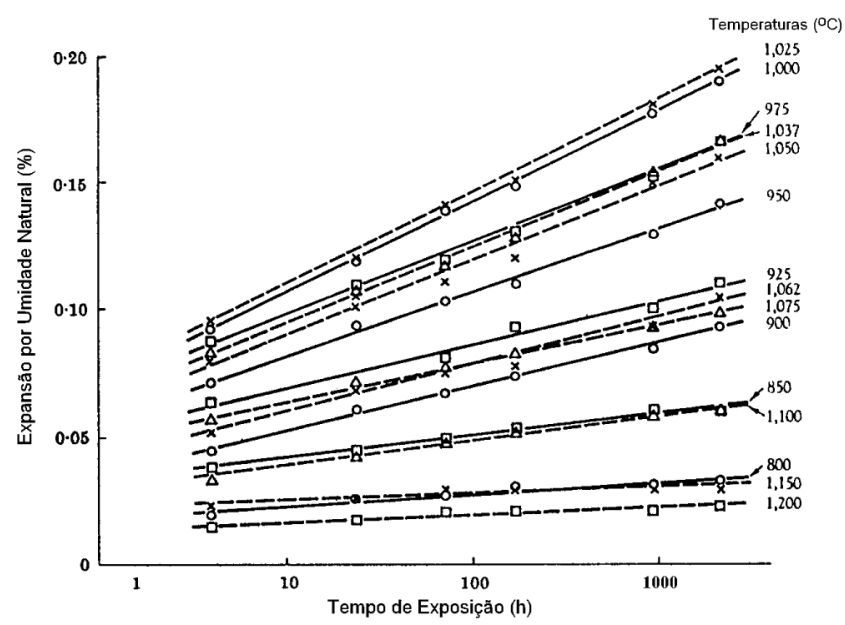

Figura 3: EPU natural para espécimes queimados entre 800 e $1200{ }^{\circ} \mathrm{C}$, em função do tempo de exposição [4].

[Figure 3: Natural ME of bodies fired between 800 and $1200^{\circ} \mathrm{C}$, versus the exposure time [4].]

Várias evidências mostram que quando medidas precisas são efetuadas, os corpos cerâmicos expandem continuamente com o tempo com a cinética que rege o fenômeno podendo ser linear como função do logaritmo do tempo. Estudos demonstraram que este tipo de relação não é incomum nas cerâmicas e na química e pode ser desenvolvida da equação de Roginsky-Zeldovitch (R-Z) [6]:

$$
d q / d t=\alpha_{1} \exp ^{\left(-b_{1} q\right)}
$$

onde, para um processo de quimisorção, $q$ é a quantidade de gás adsorvido no tempo $t$ e $\alpha_{1}$ e $b_{1}$ são constantes. 
A forma integral da equação $(\mathrm{G})$ gera a equação $(\mathrm{H})$ :

$$
q=\left(q_{0}-b_{1}^{-1} \ln k_{1}\right)+b_{1}^{-1} \ln \left(t+k_{1}\right)
$$

onde $k_{1}=\left(\alpha_{1} b_{1}\right)^{-1} \exp \left(b_{1} q_{\mathrm{o}}\right)$ se $q=q_{\mathrm{o}}$ em $t=0$.

A equação $(\mathrm{H})$ pode ser expressa na forma:

$$
q=m+n \ln \left(t+k_{1}\right)
$$

e os três parâmetros podem ser estimados de dados experimentais através do método dos mínimos quadrados.

No entanto, sendo a EPU um efeito secundário da adsorção de vapor de água na superfície do corpo, não é possível aplicar diretamente equações de cinética de reação química aos dados de EPU. Conseqüentemente, tais dados devem ser adequados a uma equação deste tipo [6]:

$$
\mathrm{E}=\mathrm{m}_{1}+\mathrm{n}_{1} \ln \left(\mathrm{t}+\mathrm{k}_{1}\right)
$$

Embora o fenômeno da EPU seja bem aceito e muitas causas fundamentais tenham sido identificadas, os mecanismos de expansão ainda não foram precisamente definidos. Nenhuma equação representa exclusivamente o avanço da EPU com o tempo de exposição; todavia, a forma integrada da equação de Roginsky-Zeldovitch é a preferida para se fazer predições a cerca da expansão natural em muitos fins práticos. Sua utilidade também tem se mostrado inestimável para permitir que dados de uma larga variedade de amostras sejam incorporados em uma só relação entre a expansão acelerada em autoclave e a expansão natural [7].

Pesquisadores mostraram (modelo de McDowall e Birtwistle) que a expansão de um tijolo até uma idade de 60 meses (5 anos) poderia ser prevista a partir de uma expansão acelerada após tratamento com vapor a $100{ }^{\circ} \mathrm{C}$ no período de 4 $\mathrm{h}$, pela equação $E_{t}=\mathrm{Z} S$, onde $\mathrm{Z}$ era expresso como uma função linear do logaritmo do tempo, com $E_{t}$ assumindo a forma [8]:

$$
E_{t}=[-0,1929+0,6013 \ln (t+2,2977)] S
$$

onde $E_{t}=$ expansão (\%) que ocorre após um período de t mês, $S=$ valor da expansão (\%) que um tijolo recém saído do forno ( 24 a $36 \mathrm{~h}$ ) sofre após um período de $4 \mathrm{~h}$ em tratamento com vapor a $100{ }^{\circ} \mathrm{C}$ e pressão atmosférica, $t=$ tempo em meses, e para previsões máximas no tempo de 60 meses, $\mathrm{Z}$ assumia o valor de 2,5, o qual refere-se a um limite de confiança de $99 \%$ para a expansão de $2,29 \mathrm{~S}$ prevista pela equação (K) nesta situação.

Embora não haja metodologia única, totalmente confiável, que possa predizer a expansão futura (5 anos) de tijolos recém saídos do forno, o método desenvolvido pela BDRI (Brick Development Research Institute, Austrália), baseado no modelo de McDowall e Birtwistle, apresenta resultados muito satisfatórios. Esse método que simplifica a equação (K) a:

$$
\mathrm{e}_{\mathrm{m}}=\mathrm{ZS}
$$

onde $\mathrm{e}_{\mathrm{m}}$ é a expansão estimada para o período de 5 anos. Ao fator $\mathrm{Z}$ foi dado inicialmente, como já mencionado, o valor de 2,5 (para as expansões em 5 anos). Todavia o BDRI observou que as expansões previstas tendiam a ser menores que as constatadas para valores de expansões medidas, $S$, menores que $0,025 \%$. $O$ fator $Z$ de 2,5 também superestimava a expansão de tijolos com valores de expansões medidas, $S$, maiores que $0,09 \%$; então, passou-se a utilizar os seguintes valores para se determinar $\mathrm{e}_{\mathrm{m}}: \mathrm{Z}=3$ para $S<0,025, \mathrm{Z}=3,38$ - (S/0,065) para $0,025<S<0,09$ e Z $=2$ para $S>0,09$.

Alguns trabalhos, todavia, indicaram ser adequada a substituição da expansão estimada para o período de 5 anos por uma expansão que seja uma estimativa para o período de 15 anos. Já que se observou falhas em construções, provavelmente devido à EPU [9], ocorrerem só após o período de 30 anos [9]. Esses autores [9] alegam que por ser um fator utilizado em projetos, no cálculo e elaboração de juntas de dilatação, uma estimativa para 15 anos forneceria maior segurança às construções.

Deve-se ressaltar que o estudo das deformações de alvenaria não se deve limitar à análise das deformações dos seus componentes isolados (tijolos, argamassa), já que a deformação total é influenciada também pelo efeito de interação entre os componentes da alvenaria, principalmente no que se refere à absorção de água e sua transferência entre os constituintes [10], bem como na absorção das tensões geradas com a EPU em virtude das deformações do sistema como um todo. Nesse sentido, vários estudos, especialmente na década de 70 e início de 80 , foram dedicados a análise da deformação de paredes de alvenaria devido a EPU dos seus constituintes [11-16]. Concluindo que, de forma geral, a razão entre a EPU da parede como um todo relativamente à EPU dos tijolos constituintes poderia variar de 0,3 a 1 , com grande parte dos estudos apresentando valores em torno de 0,6.

Desejando utilizar uma equação para prever a expansão de tijolos em até 15 anos, pesquisadores modificaram a equação original de McDowall e Birtwistle $\left(E_{t}=\mathrm{ZS}\right.$, onde $Z=-0,1929+0,6013 \ln (t+2,2977))$, já que a equação só é indicada para previsão de EPU até 5 anos (em virtude dos estudos da qual se originou terem sido realizados com tijolos durante 5 anos) [17]. Embora a nova relação tenha podido ser extrapolada além dos 15 anos, um aumento inesperado ocorria na taxa de expansão após os 15 anos. A equação utilizada era uma combinação de uma função logarítmica $\left(\mathrm{b}_{1}=\mathrm{k}_{1}+\mathrm{k}_{2} \ln \left(\mathrm{t}+\mathrm{k}_{3}\right)\right)$ e uma polinomial $\left(\mathrm{b}_{2}=\mathrm{C}_{1}+\mathrm{C}_{2} \mathrm{t}_{3} \mathrm{t}_{2}\right)$, da forma $E_{t}=\mathrm{b}_{1} S+\mathrm{b}_{2} S^{2}$, o que gerava a seguinte equação:

$\mathrm{E}_{\mathrm{t}}=-3,4 \mathrm{~S}+1,51 \ln (\mathrm{t}+11)+3,5 \mathrm{~S}^{2}-0,253 \mathrm{~S}^{2} \mathrm{t}+0,000058 \mathrm{~S}^{2} \mathrm{t}^{2}$

Comparando com dados da literatura (expansão natural de até 20 anos), a equação (M) previa valores maiores que os observados quando se fazia uso de valores elevados de $t$ e $S$, já que os termos $S^{2}$ e $S^{2} t^{2}$ aumentavam muito rápido com a elevação do $t$ e $S$, resultando valores não realistas [17]. Nesse sentido, evidenciou-se que a EPU de várias amostras 
de blocos cerâmicos, mesmo após dezenas de anos, pode ser representada através da relação clássica do tipo [17]

$$
E_{\mathrm{t}}=\mathrm{k}_{1}+\mathrm{k}_{2} \ln \left(t+\mathrm{k}_{3}\right)
$$

onde $\mathrm{k}_{3}$ corrige a curvatura da curva para pequenos tempos. Se apenas a expansão a longos tempos está sendo considerada, a contribuição de $\mathrm{k}_{3}$ diminui e aproxima-se de zero e $\mathrm{o}$ gráfico da expansão natural contra $\log t$ torna-se altamente linear, tendo grande concordância com dados de expansão natural de até vinte anos. Seguindo esse raciocínio há uma série de equações, baseadas em interpolações com dados experimentais que permitem a previsão de expansões, por interpolação, para períodos de 5 a 20 anos e por extrapolação, para períodos além de 20 anos, para várias expansões " $S$ " [17]. Essas equações não têm os problemas de extrapolação inerentes ao modelo desenvolvido utilizando combinação de equações polinomial e logarítmica.

Todavia, deve-se ressalvar que o melhor método de se prever expansões futuras é pela obtenção de dados experimentais acerca dos produtos (tratando-os como casos particulares) e a partir desses e dos modelos de equações previstos na literatura (como adequados para representar a EPU), fazer modelagens para o produto em questão e só a partir de então tentar fazer inferência de expansões futuras [17]. Não é indicado o uso de equações encontradas na literatura que se mostraram adequadas na previsão de determinados produtos, já que uma equação, que representa o comportamento de um produto, pode não ter a mesma adequação quando aplicada a outro.

Com base na relação básica definida por McDowall e Birtwistle:

$$
\mathrm{E}_{\mathrm{t}}=[a+b \ln (t+c)] S
$$

também foi desenvolvida uma equação a fim se obter uma previsão da expansão de um bloco cerâmico entre duas idades, tendo-se conhecimento da idade do tijolo no momento da construção [7]. A equação é a seguinte:

$$
\mathrm{E}_{\mathrm{c}}=\mathrm{Sb}\left[\ln \left(t_{1}+t_{2}+c\right)-\ln \left(t_{1}+c\right)\right]
$$

onde $E_{c}=$ expansão (\%) prevista $\mathrm{t}_{2}$ meses após a construção e $t_{1}=$ idade do tijolo no momento da construção em meses.

Todavia, a utilização de expansões de blocos cerâmicos recém saídos do forno ( 24 a 36 h após a saída) gera uma certa dificuldade e para esse método [7] ser universal se requer que os tijolos sejam todos datados, o que não é muito comum [8].

\section{Energia de ativação}

Uma sistemática para determinação da energia de ativação da EPU de corpos cerâmicos à base de argila foi desenvolvida na década de 70 [18]. Nessa metodologia partiu- se do pressuposto que a expansão é atribuída a adsorção de vapor de água da atmosfera e sua reação com um componente particular do corpo queimado. O componente reativo do corpo cerâmico, provavelmente um aluminosilicato alcalino, foi identificado por $\alpha$. Assumido que $\mathrm{H}_{2} \mathrm{O}$ reage com $\alpha$ para formar um hidrato, tal como mostrado abaixo:

$$
\alpha+\mathrm{H}_{2} \mathrm{O} \rightarrow \alpha \cdot \mathrm{H}_{2} \mathrm{O}
$$

e assumindo que a reação é de primeira ordem, tanto com respeito a $\alpha$ como a água, tem-se que a taxa de formação de $\alpha \cdot \mathrm{H}_{2} \mathrm{O}$ pode ser dada pela equação $(\mathrm{P})$ :

$$
\mathrm{d}\left[\alpha . \mathrm{H}_{2} \mathrm{O}\right] / \mathrm{dt}=\mathrm{k}[\alpha]\left[\mathrm{H}_{2} \mathrm{O}\right]
$$

A taxa de formação do composto hidratado vai variar com o tempo e com a temperatura. Assim, é necessário analisar como variam os três termos a direita da equação $(\mathrm{P})$ com relação à temperatura e ao tempo. A constante de reação $\mathrm{k}$ é independente do tempo mas não da temperatura. Conforme a reação prossegue, a concentração de $\alpha$ diminui, sendo função do tempo. Considerando que durante o ensaio de EPU se trabalha em temperaturas muito inferiores a temperatura de queima original, considerou-se nessa sistemática que a concentração de $\alpha$ era independente da temperatura do ensaio, enquanto que a concentração de $\mathrm{H}_{2} \mathrm{O}$ foi considerada apenas função da temperatura, já que se trabalhou sempre com câmaras em atmosfera saturada de vapor de água.

Considerando-se também que os ensaios de determinação da EPU foram realizados em condições isotérmicas, tem-se que a concentração de $\mathrm{H}_{2} \mathrm{O}$ permaneceu constante durante $\mathrm{o}$ experimento. Então, com base nessas simplificações, tem-se que a equação $(\mathrm{P})$, pode ser escrita da seguinte forma:

$$
\mathrm{d}\left[\alpha . \mathrm{H}_{2} \mathrm{O}\right] / \mathrm{dt}=\mathrm{k}^{\prime}[\alpha]
$$

onde $\mathrm{k}$ 'é a nova constante de reação, que é constante quando a temperatura do ensaio é mantida constante. Caso a temperatura mude, $\mathrm{k}^{\prime}$ assume novo valor. A influência da temperatura na constante de reação pode ser expressa por uma equação de Arrhenius

$$
\mathrm{k}=\mathrm{Ae}^{-\mathrm{E}_{\mathrm{a}} / \mathrm{RT}}
$$

que combinada com a equação (R), gera a equação (S):

$$
\mathrm{d}\left[\alpha . \mathrm{H}_{2} 0\right] / \mathrm{dt}=\mathrm{Ae}^{-\mathrm{E} / \mathrm{RT}}[\alpha]
$$

Assim, medindo a taxa conforme o hidrato é formado em uma série de diferentes isotermas, enquanto a concentração de $\alpha$ é mantida constante, pode-se determinar a energia de ativação.

Quando o hidrato $\alpha \cdot \mathrm{H}_{2} \mathrm{O}$ é formado, ocorre a expansão da amostra. Então, o trabalho de expansão realizado é diretamente proporcional à concentração de $\alpha . \mathrm{H}_{2} \mathrm{O}$ formada. 
$\mathrm{O}$ trabalho $\mathrm{W}$ é expresso por $1 / 2 \mathrm{FE}$, onde $\mathrm{E}$ é a expansão por umidade da amostra (deformação linear) e $\mathrm{F}$ é a força necessária para expandir a amostra. Já que a deformação da amostra está provavelmente dentro dos limites de deformação elástica do corpo cerâmico, tem-se que $F$ também será proporcional a E, obtendo-se assim a seguinte proporcionalidade:

$$
\left[\alpha \cdot \mathrm{H}_{2} \mathrm{O}\right]=\mathrm{B} \mathrm{E}^{2}
$$

onde B é uma constante.

Já que a EPU pode ser expressa pela equação (J) e considerando nula a constante $\mathrm{k}_{1}$ nessa equação, tem-se que:

$$
\mathrm{dE} / \mathrm{dt}=\mathrm{b} / \mathrm{t}
$$

onde $\mathrm{b}$ é uma constante qualquer.

Combinando a derivada da equação (T) com as equações (U) e (S) obtém-se a seguinte equação:

$$
\mathrm{b} / \mathrm{t}=\mathrm{Qe} \mathrm{e}^{-\mathrm{E} / \mathrm{RT}}
$$

onde $\mathrm{Q}$ é $\mathrm{A}[\alpha] / 2 \mathrm{E}$.

Então, considerando um grupo de amostras "idênticas" (mesmas matérias-primas e processamento) que tenham sofrido a mesma EPU, ter-se-á que Q será constante nesse grupo de amostras e, analisando a razão b/t em função do inverso da temperatura, pode-se obter a energia de ativação da EPU. Vale ressaltar que essa energia de ativação se refere à energia inerente ao processo de expansão subseqüente à rápida expansão que ocorre nas primeiras horas após a saída do forno. O que fica evidente ao se lembrar que a constante $\mathrm{k}_{1}$ da equação ( $\mathrm{J}$ ) foi considerada zero.

As Figs. 4 e 5 ilustram resultados obtidos, utilizando-se essa sistemática [18] para determinar a energia de ativação da EPU. A Fig. 4 ilustra a EPU de um conjunto de amostras (idênticas) obtidas sob várias condições, sendo utilizada a tangente desses gráficos (em valor de E constante) para se obter b, enquanto que a Fig. 5 ilustra as curvas b/t versus o inverso do tempo, sendo suas tangentes utilizadas para determinação da energia de ativação.

Foi observado que os valores da energia de ativação variavam de 70 a $75 \mathrm{~kJ} / \mathrm{mol}$, valores semelhantes, segundo os autores, à energia de ativação para difusão da água em sílica vítrea [18]. Em uma das amostras estudadas foi observado um pequeno aumento da energia de ativação com o aumento da temperatura de queima (faixa de temperatura de 975 a $1050{ }^{\circ} \mathrm{C}$ ), enquanto que nas demais a energia permaneceu praticamente constante com relação à temperatura de queima.

Recentemente, no entanto, pesquisadores, utilizando essa mesma sistemática, evidenciaram uma diminuição da energia de ativação com o aumento da temperatura de queima na faixa de 900 a $1100{ }^{\circ} \mathrm{C}$ (as matérias-primas dos corpos cerâmicos

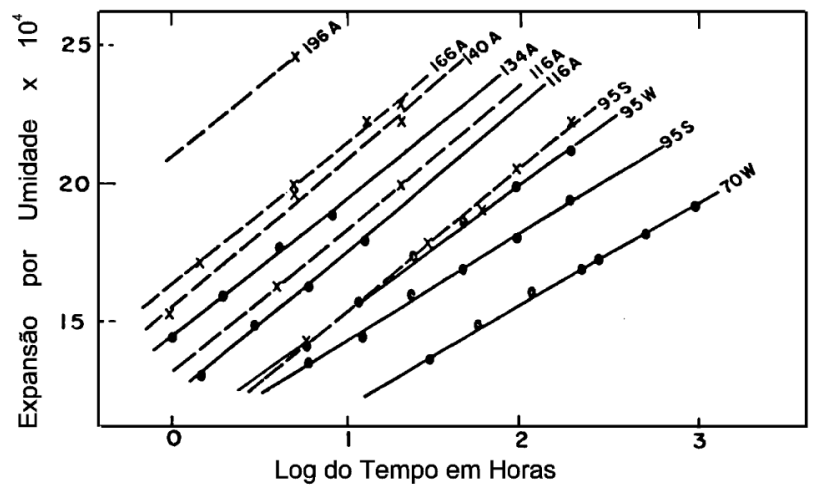

Figura 4: EPU de amostras submetidas a várias condições de tratamento. A indica autoclave, $\mathrm{S}$ indica ambiente saturado com vapor e $\mathrm{W}$ indica emersão em água. $\mathrm{O}$ número antes de cada letra indica a temperatura do ensaio em ${ }^{\circ} \mathrm{C}$ [18].

[Figure 4: ME: A autoclaved; $S$ steaming; $W$ water immersed. The numbers before the letters stand for the temperature of the test $\left({ }^{\circ} \mathrm{C}\right)$ [18].]

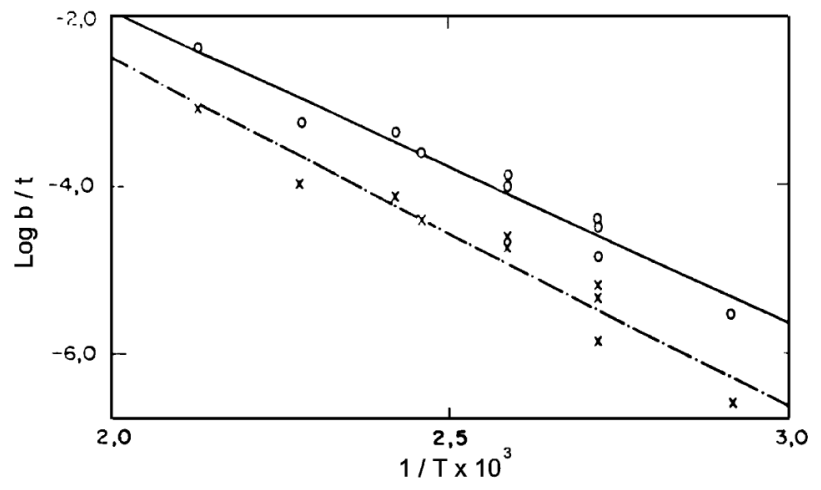

Figura 5: Relação b/t versus o recíproco da temperatura absoluta[18].

[Figure 5: Relation b/t versus the reciprocal of the absolute temperature [18].]

eram constituídas basicamente por argila, mica, quartzo e feldspato) e um posterior aumento da energia de ativação com a queima a $1200{ }^{\circ} \mathrm{C}$ [19]. Esses resultados evidenciam a influência da temperatura de queima e características microestruturais (tipo de fases e suas quantidades) na cinética da reação de adsorção. Os valores de energia de ativação obtidos nesse trabalho [19] foram inferiores aos encontrados em [18], variando de 20 a $60 \mathrm{~kJ} / \mathrm{mol}$.

\section{Determinação da expansão por umidade}

A determinação da EPU engloba três pontos distintos: a determinação da expansão natural do material, que é realizada através da medida do comprimento inicial do corpo cerâmico logo após sua saída do forno, e subseqüentes medições ao longo tempo de exposição em condições 
ambiente ou controlada; determinação da expansão já sofrida pelo corpo cerâmico desde o processo de fabricação, que é muito importante quando se deseja determinar se a falha de um produto foi influenciada ou não pela EPU e é determinada através da medida do comprimento inicial do corpo, requeima do material e nova medição; e determinação da expansão futura (ou em potencial) do material, que é em geral obtida após exposição de peças cerâmicas requeimadas ou recém saídas do forno a um ensaio de autoclavagem, fervura ou exposição ao vapor, e tem por fim tentar prever a expansão em potencial do produto através de um ensaio em condições mais severas que a ambiente e em um curto intervalo de tempo.

A medição das dimensões, antes e após os ensaios, é em geral efetuada por instrumentos com resolução de $0,01 \mathrm{~mm}$, tais como micrômetro, relógio comparador, transdutor ou dispositivos similares. Nesse sentido, a dilatometria é uma importante ferramenta na medição da EPU dos materiais cerâmicos, possibilitando uma melhora na precisão das determinações $[20,21]$. Por isso essa técnica vem sendo utilizada sistematicamente para determinação da EPU em empresas e laboratórios de pesquisa. Todavia, desde a década de 30 [22] a expansão térmica é utilizada na determinação da EPU de materiais cerâmicos, tendo esta técnica adquirido maior evidência com o desenvolvimento de equipamentos que possibilitem uma maior precisão nos resultados. Vale salientar que uns dos primeiros trabalhos a utilizar a dilatometria para o estudo da EPU de massas cerâmicas comerciais se deu na década de 60 [23]. Adilatometria fornece informações valiosas a respeito de fenômenos susceptíveis de ocorrerem quando o material sob estudo é progressivamente aquecido, e em casos específicos certas informações podem ser igualmente obtidas com o resfriamento da amostra depois do tratamento térmico [24]. As curvas dilatométricas registram as alterações dimensionais da amostra, sejam elas simplesmente ligadas aos valores dos coeficientes de dilatação (térmica), sejam devidas às variedades de fenômenos que podem ocorrer durante o aquecimento, entre os quais reações e transformações estruturais, sinterização, formação de fases viscosas ou líquidas, fluência e eliminação de constituintes, como por exemplo água.

A Fig. 6 ilustra uma curva típica de dilatometria para determinação da EPU. Esse gráfico mostra uma curva onde ocorre uma reversão da EPU do material após aquecimento a aproximadamente $500^{\circ} \mathrm{C}$, sendo essa, medida pela diferença entre os pontos inicial e final da curva. Pode-se observar que a curva dilatométrica não descreve o mesmo caminho durante o aquecimento e o resfriamento. Essa diferença de comportamento está associada à eliminação da água adsorvida presente na amostra durante o aquecimento com a subseqüente retração, o que é evidenciado pela inflexão da curva de aquecimento por volta de $150^{\circ} \mathrm{C}$.

Um ponto que se deve ter em mente durante a determinação da EPU dos materiais é a temperatura das peças e dos instrumentos de medida no momento das medições, a fim

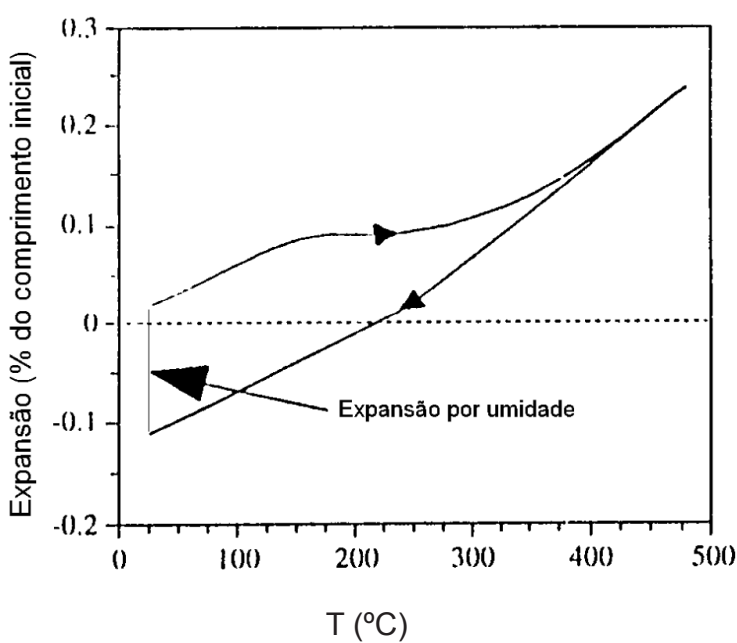

Figura 6: Curva típica de peça que sofreu EPU [20].

[Figure 6: Characteristic dilatometric curve of a body that has experienced $M E$ [20].]

de se evitar variações dimensionais oriundas de oscilações térmicas, que influenciem as determinações da EPU [25], propiciando-se assim reprodutibilidade e maior credibilidade ao ensaio. Estudos já observaram que se não forem tomados cuidados no controle da temperatura, no sentido de que as medidas inicial e final sejam tomadas na mesma temperatura, pode ocorrer o falseamento nos valores determinados para a EPU $[12,16,26]$. Nesses estudos observou-se que oscilações na temperatura das peças correspondiam diretamente a variações nas expansões medidas, estando essas flutuações associadas não apenas à dilatação térmica das amostras, mas também a dos equipamentos de medição. Assim, indicase que todas as medições sejam realizadas em ambiente com temperatura constante (com variação de $\pm 1^{\circ} \mathrm{C}$ ), com as amostras, evidentemente, deixadas adquirir equilíbrio térmico com o meio. Vale salientar que quando a umidade flutua significativamente, algum controle de umidade também é desejável [26].

Algumas outras peculiaridades podem influenciar no resultado final do ensaio de determinação da EPU de corpos cerâmicos. É o caso da secagem dos corpos de prova antes do ensaio de requeima e após o ensaio de aceleração da EPU (vapor, autoclavagem, fervura). A secagem é importante porque a taxa de expansão do material aumenta rapidamente com a temperatura da umidade em contato com o corpo, o que pode levar a expansão durante a secagem, enquanto houver água livre na peça e por conseguinte a valores falseados da EPU do material [27]. Então, quanto mais umidade possuir a peça, mais crítico será o processo de secagem. Nesse sentido, processos de corte a úmido devem ser preferencialmente evitados.

O desgaste também pode influenciar nos resultados de determinação da EPU [28]. Foi observado que, apesar de extremamente leve, o desgaste das pontas das agulhas de aço dos relógios comparadores, bem como da superfície das amostras, pode conduzir a falhas nas medições da EPU 
[26]. É indicado para minimizar esse desgaste o polimento da ponta das agulhas antes e após a medição.

AEPUéumfenômenocuja determinaçãoestánormalizada [29-32], mas com enfoque em placas de revestimento cerâmicos. Estas normas prescrevem a determinação da EPU passada e da EPU futura de revestimentos cerâmicos, através da sua requeima e subsequiente exposição a água em condições controladas (autoclavagem ou fervura).

Por serem as normas ISO e Européias (EN) as mais internacionalmente conhecidas e servirem de referência para pesquisadores em todo o mundo, vale a pena ressaltar algumas diferenças entre elas. Placas esmaltadas foram incluídas na metodologia de ensaios da ISO, o método de ensaio não é apenas restrito para placas com absorção de água entre 6 e $10 \%$, o tamanho dos corpos de prova da EN foram adotados como tamanho mínimo dos corpos de prova, o número de espécimes foi reduzido de 7 para 5 nas normas e o procedimento de requeima foi alterado de $4 \mathrm{~h}$ a $600{ }^{\circ} \mathrm{C}$ (com velocidade de aquecimento de $50{ }^{\circ} \mathrm{C} / \mathrm{h}$ ) para $2 \mathrm{~h}$ a 500 ${ }^{\circ} \mathrm{C}$ (com velocidade de aquecimento de $150^{\circ} \mathrm{C} / \mathrm{h}$ ) nas normas ISSO. Não há limites exigidos e sim apenas um informativo que diz que EPUs maiores que $0,6 \mathrm{~mm} / \mathrm{m}$, podem contribuir para problemas com os revestimentos cerâmicos [33] nas normas ISO.

A normalização brasileira, NBR 13818, tem por base as normas ISO, prescrevendo requeima a $550^{\circ} \mathrm{C}$ por $2 \mathrm{~h}$ e ensaio de fervura por $24 \mathrm{~h}$ para determinação da EPU. E, tal como a norma ISO, não determina um valor limite para a EPU de revestimentos cerâmicos, fazendo apenas um adendo, indicando que EPUs acima de $0,6 \mathrm{~mm} / \mathrm{m}$ podem contribuir para problemas de falha em serviço, caso sejam utilizadas práticas de fixação insatisfatórias ou as peças estejam sob certas condições climáticas.

\section{Determinação da expansão sofrida}

Muito embora a EPU seja um tema a muito discutido e já presente na normalização, existe ainda algum potencial para controvérsias no que diz respeito aos métodos utilizados para a determinação da EPU. Historicamente, existem duas escolas de pensamento baseadas no reaquecimento a baixas e altas temperaturas. Admite-se que a EPU é principalmente devido à adsorção física e química da umidade no interior do corpo cerâmico. Assim, é lógico que se use um tratamento de reaquecimento para remover essa água. Todavia, o processo de adsorção inicia tão logo os produtos começam a resfriar ainda no interior do forno, portanto, deve-se estabelecer um ponto de referência para o início da medida, que permita prever a EPU natural do corpo bem como avaliar a sua expansão passada [20]. Nesse sentido, a magnitude da EPU determinada dependerá do momento em que se realiza a medida inicial, principalmente no que se refere à EPU natural. Assim, o ciclo de resfriamento, a temperatura de saída do forno e as condições de armazenamento após saída do forno, irão todos influenciar na magnitude determinada [1].
A medição da EPU "absoluta" requer algum método que possibilite o resfriamento das amostras no final de seu ciclo de queima em atmosfera anidra. Alternativamente [26], a medição pode tomar com referência algum intervalo de tempo após a saída das peças do forno, por exemplo $24 \mathrm{~h}$, ignorando assim, a rápida expansão inicial que ocorre nas primeiras horas após a saída das peças do forno. Na prática, ignorar essa expansão inicial, que ocorre nas primeiras horas, parece razoável, já que é bem pouco provável que as peças cerâmicas sejam postas em uso em tão curto período de tempo depois da saída do forno [26]. No entanto, do ponto de vista da analise da cinética de expansão das peças, esse procedimento pode comprometer a determinação do comportamento de expansão do corpo cerâmico.

A determinação da EPU envolve ainda outros fatores complicadores. Durante a exposição ao ambiente surgem microtrincas no interior de muitas peças devido ao alívio de tensões térmicas, e isso pode resultar em uma expansão irreversível. Cargas externas, sais e o congelamento de água no interior do corpo cerâmico também podem induzir à expansão. Ainda se precisa determinar até que ponto a expansão provocada por esses mecanismos é reversível, mas podese prever de antemão, que seriam necessárias temperaturas relativamente elevadas para provocar a "resinterização" das microtrincas, que os sais podem atuar como catalisadoras para contração e que temperaturas muito elevadas podem induzir ao início da sinterização e outras reações.

Foram observadas histereses na requeima (utilizando dilatometria), e sabe-se que quando se reaquece um material composto por agregados heterogêneos de cristais anisotrópicos, os grãos se expandem desigualmente nas diferentes direções, dando origem a espaços vazios (microtrincas). Quando do resfriamento, esses espaços vazios tendem a fechar-se mas nunca conseguem reproduzir os mesmos movimentos do aquecimento, de modo que alguns espaços permanecem, havendo variação permanente das dimensões. Através de análise de curvas dilatométricas, pode-se concluir que retrações não características, nos ciclos de queima que passam pela temperatura de inversão do quartzo, também são manifestações desse fenômeno [20, 21]. Em alguns casos, tem-se provado impossível remover a expansão total sem aquecimentos a temperaturas próximas ou até acima das temperaturas originais de queima. Nessas temperaturas, todavia, mais retração de queima ocorre e a distinção entre os dois efeitos (retração devido à perda da água adsorvida e aquela devido a uma melhor queima) torna-se muito difícil [34]. Estudos dilatométricos têm evidenciado que nesses casos parte da retração é devida à sinterização em elevadas temperaturas e que mudanças de fases podem ocorrer [35]. Assim, a expansão aparentemente por umidade, medida por diferença entre os comprimentos antes e depois de reaquecimento em temperaturas elevadas, pode ser representada como função da quantidade recuperada de EPU, mas também por variações térmicas, devidas a efeitos de inversão do quartzo, diferenças de 
coeficientes de dilatação térmica, transformações de fases, retração por sinterização e, em alguns casos, início da EPU após o reaquecimento [20]. Isto sugere que reaquecimentos devem evitar temperaturas maiores que a de inversão do quartzo. Todavia, é necessário aquecimento suficientemente elevado para que seja removida a umidade adsorvida. Então, temperaturas entre 400 e $550{ }^{\circ} \mathrm{C}$ parecem satisfazer esse requerimento [36].

Todavia, estudos advogam que reaquecimentos em temperaturas da ordem de $500{ }^{\circ} \mathrm{C}$ não fornecem a expansão total sofrida pelo corpo já que não o conduz a um estado semelhante ao da saída do forno, ressaltando ainda, que a cinética de re-expansão desses corpos após queima não é igual à cinética de expansão original (requeima a $500{ }^{\circ} \mathrm{C}$ não induz o mesmo grau de rápida expansão inicial que caracteriza os corpos cerâmicos logo depois da saída do forno) [37]. Assim, nem a estimativa de expansão passada, nem a estimativa da EPU potencial conteriam a rápida expansão inicial [1, 33]. Nesses estudos sugere-se temperaturas de requeima da ordem de $900{ }^{\circ} \mathrm{C}$, indicando que essas temperaturas fornecem valores de EPU equivalentes a cerca de $90 \%$ da EPU sofrida pelo corpo desde o resfriamento no forno e que os valores obtidos com a requeima a $500{ }^{\circ} \mathrm{C}$ subestimam a expansão do corpo em no mínimo $0,01 \%(0,1 \mathrm{~mm} / \mathrm{m})$ [35].

No que se refere à influência da inversão do quartzo na determinação da EPU, essa corrente argumenta que a possível expansão permanente provocada pela inversão do quartzo (descolamento do quartzo da matriz vítrea) quando da requeima em temperaturas maiores que $573{ }^{\circ} \mathrm{C}$, só é observada em corpos de textura grosseira queimados em temperaturas inferiores a $1000{ }^{\circ} \mathrm{C}$. E que devido às características de fina textura e altas temperaturas de queima dos corpos cerâmicos modernos, o efeito de expansão provocado pela inversão do quartzo é pouco provável de influenciar a determinação da EPU [37].

Entretanto, já foi confirmado que o reaquecimento a 900 ${ }^{\circ} \mathrm{C}$ por $1 \mathrm{~h}$ pode superestimar a expansão passada da peça, aparentemente induzindo retrações não associadas a expansão por umidade, particularmente em corpos muito vitrificados [37]. Ademais, deve-se esperar que a quantidade de fases amorfas diminua com o reaquecimento, já que possui uma taxa de resfriamento bem menor que no caso da queima rápida (forma de queima comum, atualmente, no processamento de revestimentos cerâmicos). O que alteraria a EPU final da peça, no caso da análise da EPU "potencial" do material (requeima seguida por ensaio de aceleração da EPU).

Estudos demonstram que o grau de retorno de um corpo cerâmico às suas dimensões originais, após tratamento térmico, depende não apenas da temperatura de requeima a que é submetido, mas também da duração deste tratamento, da composição do corpo e da temperatura e taxa de aquecimento a que foi submetido na queima original, indicando não haver, aparentemente, um método único para prever com precisão a EPU passada [33].

Deve-se ressaltar que é difícil, e geralmente impossível, remover o gás químiadsorvido completamente, a não ser que o sólido seja aquecido em altas temperaturas, o que poderá alterar a capacidade de sorção do sólido. O que evidencia, mais uma vez, a dificuldade em se atingir o estado original da peça recém saída do forno através de um processo de requeima, e que é extremamente complicado a utilização de apenas um tipo de tratamento térmico (uma temperatura e um tempo e patamar) em todo tipo de cerâmica [1].

\section{Determinação da expansão em potencial}

$\mathrm{O}$ ensaio de autoclavagem em elevadas temperaturas e pressões tem sido utilizado para a previsão da EPU após longos períodos de tempo, através da aceleração da expansão dos corpos cerâmicos. Um ensaio deste tipo é desejável a fim de se tentar predizer o comportamento de produtos em serviço. Todavia, a utilidade do ensaio é posta a prova quando se analisa que a EPU é causada pela adsorção de água ao corpo, já que a adsorção é um fenômeno que é afetado por temperatura, pressão, tipo de vapor e natureza da superfície do sólido, sendo então imaginável que temperaturas e pressões bem acima das condições de serviço poderão fornecer dados de expansão não realísticos [38], no que se refere às condições ambiente.

Há evidências que em alguns casos ocorre um aumento progressivo da área específica interna com o tratamento em autoclave. Acredita-se que a adsorção contínua da água na fase vítrea pode prosseguir por longos períodos de tempo. Neste contexto, foi observado que uma dada quantidade de água absorvida em temperatura ambiente e através de tratamento em autoclave pode conduzir a variações de tamanhos diferentes. O que reforça a hipótese que os resultados de EPU obtidos por tratamento em autoclave podem ser inadequados como guias da expansão em condições ambiente [39], já que a utilização de elevadas temperaturas e pressões no ensaio de EPU não simula o comportamento das espécies quando expostas ao vapor de água a temperatura ambiente [40].

Ademais, trabalhos evidenciam que se dois corpos cerâmicos são ensaiados em autoclave para determinação da EPU, o corpo cerâmico com a menor EPU após autoclavagem pode não ser o que tem menor expansão em condições de serviço [41]. Infelizmente, este é um dos poucos ensaios de "aceleração" disponível, continuando a ser muito utilizado para fornecer alguma idéia a cerca das características do corpo cerâmico. O problema é que a EPU sob condições normais é um processo lento. Então, no desenvolvimento em laboratório e em controles de qualidade é necessário aplicar condições que acelerem este processo. $\mathrm{O}$ ensaio em autoclave por gerar condições extremamente severas e até por uma questão histórica (já vem sendo utilizado há muito tempo e possui uma vasta gama de dados comparativos) tornou-se costume por parte de muitas fábricas e laboratórios. Após a criação da NBR 13818 (e de toda normalização internacional) o ensaio em autoclavagem passou ser muito mais utilizado nas universidades e centros de pesquisa do que em fábricas. 
A Fig. 7 mostra a EPU de um corpo poroso de cerâmica branca sob várias condições de exposição. Pode-se observar que aEPU após 800 dias ainda continua a uma taxa aproximadamente constante, quando da exposição em água e em atmosfera normal, sendo de se esperar que as condições de serviço situem-se entre estas duas curvas. Já a expansão a altas pressões se desenvolve em um período de tempo bem menor com uma taxa de expansão bem maior que nos outros dois casos.

A Fig. 8 ilustra a EPU de um outro corpo de cerâmica branca porosa quando exposto a condições de autoclavagem diferentes, evidenciando-se que as formas das curvas de expansão são semelhantes às observadas na Fig. 7, todavia com magnitudes de expansão bem maiores em tempos de

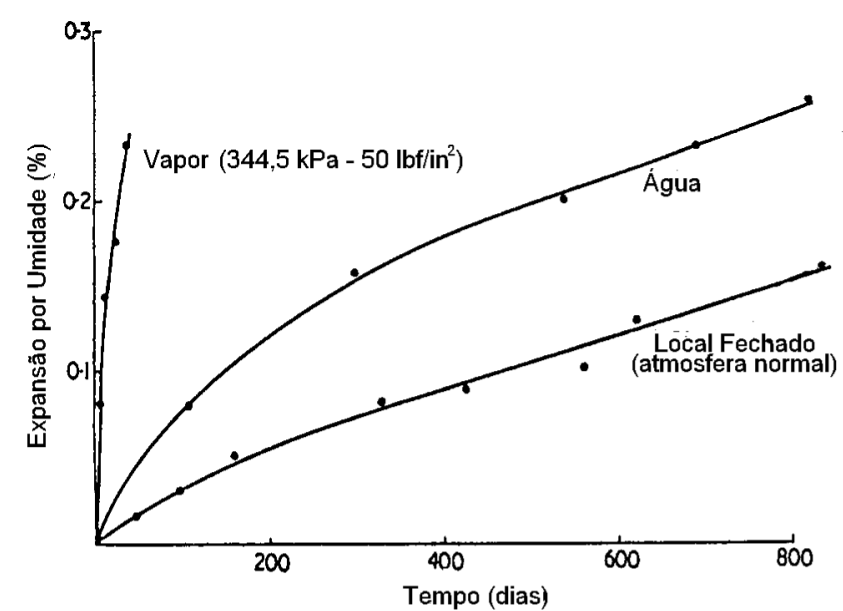

Figura 7: EPU de cerâmica branca porosa para diferentes condições de exposição [42].

[Figure 7: ME of whiteware ceramic [42].]

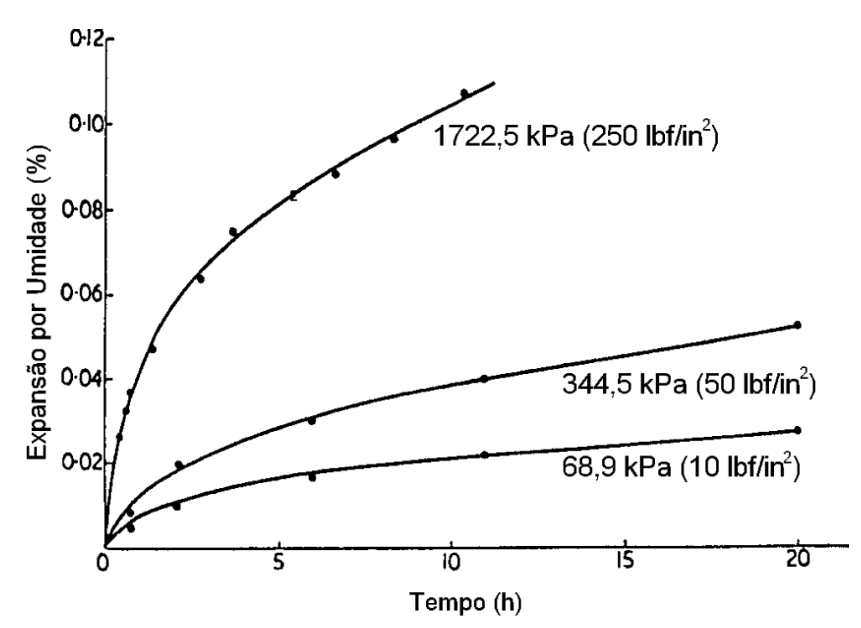

Figura 8: EPU de corpo poroso após autoclavagem em diferentes pressões [42].

[Figure 8: ME of ceramic porous bodies after different conditions of autoclaving [42].] exposição bem menores.

Um ensaio também muito utilizado na determinação a expansão potencial é a exposição dos corpos cerâmicos em ambiente saturado de vapor de água, a $100{ }^{\circ} \mathrm{C}$, mas, diferentemente da autoclavagem, em atmosfera (pressão) normal. Esse tipo de ensaio foi muito utilizado, especialmente na Austrália e Reino Unido, para a previsão da EPU futura de peças cerâmicas, já que muitos estudos indicam que a expansão obtida se correlaciona bem mais efetivamente com a expansão natural que aquela obtida por autoclavagem, o que provavelmente está relacionado ao fato das reações de expansão durante o tratamento com vapor serem, aparentemente, similares às que ocorrem quando da exposição em condições naturais [43].

O estudo da correlação entre a expansão obtida após ensaio de exposição a vapor e a EPU natural desenvolveuse mais intensamente na Austrália. Onde, por meio de equações semelhantes às mencionadas anteriormente (equações (K), (L) e (M)) foi possível a previsão de valores que se correlacionaram muito bem com expansões naturais após 4 anos.

Diferentemente do ensaio de exposição a vapor, no ensaio de fervura os corpos cerâmicos estão imersos em água e o sistema é submetido a um período de fervura que, à semelhança dos ensaios mencionados anteriormente, busca acelerar o processo de EPU. A fervura é o ensaio constante na normalização brasileira e nas normas ISO para determinação da EPU. O ensaio de fervura possui algumas controvérsias, com pesquisadores indicando que as condições do ensaio não propiciam a obtenção da verdadeira expansão em potencial do material, por possuir condições bem menos severas que a autoclavagem. Estima-se que uma fervura de $24 \mathrm{~h}$ induza uma expansão equivalente a uma expansão natural de 36 meses [33]. Deve-se ter em mente que se for ser usado tratamentos de fervura ou vapor a fim de se prever a expansão futura de peças cerâmicas, deve-se estabelecer alguma correlação com resultados da expansão natural a fim de se obter indicações confiáveis das previsões [20].

A escolha de um ou outro ensaio estava muito condicionada aos fins a que se destinavam as determinações de EPU potencial dos materiais. Por exemplo, em testes rápidos visando avaliar o comportamento de EPU em condições de fábrica utilizavam-se autoclavagem; análises mais voltadas ao estudo de correlações e cinéticas de expansão utilizavam-se da autoclavagem, exposição a vapor e acompanhamento da EPU natural. No entanto, a partir da instituição da norma definindo a fervura como ensaio para prevê a EPU futura do corpo cerâmico (a norma foi instituída para revestimentos), passou-se a utilizar predominantemente essa metodologia em centros de pesquisa e fábricas. O que está relacionado tanto ao fato de se tratar de uma necessidade normativa, bem como pela necessidade de dados comparativos entre a EPU natural e os resultados obtidos por fervura, a fim 
de se obter mais credibilidade nas suas correlações.

\section{CONCLUSÕES}

A expansão por umidade (EPU) de materiais cerâmicos vem sendo extensivamente estudada desde as primeiras décadas do século passado em virtude de sua possível influência em danos a estruturas de alvenarias, gretamento de vidrados e destacamento de revestimentos cerâmicos, observada em vários países do mundo. Com base no levantamento de resultados realizado neste artigo, pode-se concluir que, no que tange a cinética do processo de expansão, constatou-se que o fenômeno é caracterizado por uma rápida expansão no período logo após a fabricação da peça (dias ou horas) e uma subsequiente expansão com uma taxa sensivelmente menor, que pode se processar por dezenas de anos. Essa segunda etapa da expansão pode ser regida por equações lineares, da expansão em função do logaritmo do tempo. No que se refere à determinação da EPU, pode-se concluir que os procedimentos englobam basicamente dois pontos: a determinação da EPU sofrida pelo material até o presente momento, que é realizada por um processo de requeima; e a determinação da possível expansão futura do material, que é realizada através de ensaios que buscam acelerar o processo, tais como a fervura e a autoclavagem. E que, apesar da grande quantidade de trabalhos abordando o fenômeno de EPU de corpos cerâmicos, muitas controvérsias ainda existem quanto aos seus procedimentos de determinação, não havendo ainda consenso entre os pesquisadores acerca do procedimento de requeima mais adequado, bem como do ensaio mais adequado para a aceleração da EPU. Com o ensaio de fervura, presente na normalização, não aparentando fornecer valores de EPU, que possam ser usados com confiança como estimativa da real EPU potencial da peça (após dezenas de anos em serviço).

\section{REFERÊNCIAS}

[1] R. Bowman, Ceramica Acta 5, 4-5 (1993) 37

[2] H. Thimecke, J. Am. Ceram. Soc. 27, 12 (1944) 355.

[3] J. S. Hosking, H. V. Hueber, Nature 182, 4643 (1958) 1142.

[4] W. F. Cole, Nature 192, 4804 (1961) 737.

[5] W. F. Cole, J. Am. Ceram. Soc. 45, 9 (1962) 428.

[6] W. F. Cole, R. Birtwistle, Am. Ceram. Soc. Bull. 48, 12 (1969) 1128.

[7] R. Bowman, J. Aust. Ceram. Soc. 21, 1 (1985) 13.

[8] W. F. Cole, J. Aust. Ceram. Soc. 22, 1 (1986b) 55.

[9] S. Zsembery, T. Mcneilly, Key Eng. Mater. 53-55 (1991) 202.

[10] J. P. Forth, J. Brooks, S. H. Tapsir, Cement \& Concrete Composites 22 (2000) 273.

[11] R. G. Smith, Trans. Brit. Ceram. Soc. 92, 6 (1993) 233.

[12] A. Thomas, Trans. Brit. Ceram. Soc. 70, 1 (1971) 35.

[13] R. G. Smith, Trans. Brit. Ceram. Soc. 72 (1973) 191.

[14] R. Beard, A. Dinnie, A. B. Sharples, Trans. Brit. Ceram.
Soc. 82, 3 (1983) 82.

[15] R. C. De Verkey, Trans. Brit. Ceram. Soc. 82, 2 (1983) 55.

[16] K. Ficher, Trans. Brit. Ceram. Soc. 82, 2 (1983) 55.

[17] W. F. Cole, J. Aust. Ceram. Soc. 24, 1 (1988) 81.

[18] M. G. Howden, Trans. Brit. Ceram. Soc. 76, 2 (1977) 27.

[19] M. A. Carvalho, A. M. Segadães, Key Eng. Mater. 264268 (2004) 1581.

[20] R. Bowman, Ind. Ceram. 16, 2 (1996) 89.

[21] R. Bowman, Cerâmica Industrial 1, 4/5 (1996) 25.

[22] H. G. Schurecht, J. Am. Ceram. Soc. 11, 5 (1928) 271.

[23] M. Inzigneri, E. Fusarini, Trans. VII Int. Ceramic Congress (1960) p. 53.

[24] G. Cizeron, Cerâmica 25, 111 (1979) 62.

[25] J. W. McBurney, Proc. Am. Soc. Test. Mater. 54 (1954) 1219.

[26] J. Lomax, R. W. Ford, Trans. Brit. Ceram. Soc. 82, 3 (1983) 79 .

[27] J. S. Hosking, H. V. Hueber, Trans. Brit. Ceram. Soc. 59 (1960) 107.

[28] G. R. Rigby, Trans. Brit. Ceram. Soc. 33 (1934) 527.

[29] Associação Brasileira de Normas Técnicas (ABNT) NBR

13818, Placas cerâmicas para revestimento - Especificação e métodos de ensaios, Rio de Janeiro (1997).

[30] European Standard EN 155, Ceramic tiles Determination of Moisture Expansion Using Boiling Water - Unglazed tiles (1991).

[31] International Organization for Standardization ISO 10545, Ceramic Tiles - Part 1 - 16 (1999).

[32] American Standard ASTMC370-56, Test Method for Moisture Expansion of Fired Whiteware Products (1994).

[33] R. Bowman, The Need for Establishing a Moisture Expansion Convention for the Analysis of Tiling System Failures, www.dbce.csiro.au (24/03/1999).

[34] J. S. Hosking, H. V. Hueber, Nature 184, 4696 (1959) 1373.

[35] R. Bowman, Moisture Expansion Kinetics as a Function of Conditioning, www.infotile.com.au (25/03/1999).

[36] G. C. Robinson, Am. Ceram. Soc. Bull. 64, 5 (1985) 712.

[37] W. F. Cole, J. P. Banks, Key Eng. Mater. 53-55 (1991) 185.

[38] J. E. Young, W. E. J. Brownell, J. Am.. Ceram. Soc. 42, 12 (1959) 571.

[39] F. Vaughan, A. Dinsdale, Nature 183, 4661 (1959) 600.

[40] R. Harrison, A. Disndale, Trans. Brit. Ceram. Soc. 63, (1964) 63.

[41] F. E. Bernett, Am. Ceram. Soc. Bull. 55, 12 (1976) 1039.

[42] M. Cornwall, J. B. Everill, Trans. Brit. Ceram. Soc. 78, 96 (1979) R12.

[43] I. L. Freeman, R. G. Simth, Moisture Expansion of Structural Ceramics I - Unrestrained Expansion, Trans. Brit. Ceram. Soc. 66, 1 (1967) 13.

(Rec. 17/11/2004, Rev. 25/04/2005, Ac. 05/08/2005) 